Published in: Journal of Constructional Steel Research, 67(10), 1537-1544.

DOI: http://dx.doi.org/10.1016/j.jcsr.2011.03.028

\title{
Steel silos with different aspect ratios: \\ I - behaviour under concentric discharge
}

\author{
A.J. Sadowski \& J.M. Rotter
}

\begin{abstract}
The current European standards for the design of thin-walled metal silos require the designer to use a complex combination of rules covering many different aspects of loading, structural behaviour and strength. Each individual rule was often developed autonomously, usually with implicit and undocumented conservative assumptions. When combined, the overall factor of safety of a designed silo may be significantly different from that guaranteed by the standard, making it difficult to reproduce the design rules in a numerical calculation that does not include the same implicit assumptions.
\end{abstract}

This paper explores the behaviour of five thin-walled cylindrical silos with stepwisevarying wall thickness and aspect ratios varying from very squat to very slender, all custom-designed for and analysed under the EN 1991-4 (2006) concentric discharge loading condition. The aspect ratio plays a deciding role in both the behaviour and design of silos, and it is important to ascertain that a finding that is valid for one is transferable to the others. The nonlinear finite element analyses reveal that the computed load factor exceeds the partial safety factor in design by a large factor over a wide range of aspect ratio, suggesting that the overall design process is particularly conservative. The reasons for these discrepancies are explored.

This paper is the first of a pair. The second paper explores the behaviour of the same set of example silos under the EN 1991-4 eccentric discharge loads, with fundamentally different conclusions.

Keywords: concentric discharge, silos, shell buckling, plasticity, aspect ratio, design of steel structures. 
Published in: Journal of Constructional Steel Research, 67(10), 1537-1544.

DOI: http://dx.doi.org/10.1016/j.jcsr.2011.03.028

\section{Introduction}

The design of thin-walled metal silos is a complex process that pieces together many different structural considerations. The current design rules for the strength and stability of shell structures are those of the European standard EN 1993-1-6 (2007), while the design of silos specifically is covered by load cases given in EN 1991-4 (2006) and strength design requirements in EN 1993-4-1 (2007). Together, these three standards define the loading on the structure, the relationship between loading and resistance and finally the calculations that attempt to safely predict the resistance of the structure itself, taking into account the many different possible mechanisms of failure, but especially buckling. Furthermore, individual design rules for each part of the entire assessment are usually developed autonomously and often with implicitly assumed margins of safety to account for uncertainty or experimental scatter. When a collection of these rules is invoked to design a structure, its actual margin of safety may be different from what is notionally assumed in the standard. Thus the empirical origin of many of the EN design rules presents significant problems in the calibration of the design rules with a numerical calculation.

In cylindrical silos under concentric discharge, axial compression in the silo wall is caused by friction between the wall and the stored granular solid. The compressive axial membrane stress resultant is cumulative with depth, so that the risk of buckling is substantially increased towards the base of the silo. Further, it is widely recognised that the buckling strength of a shell under axial compression is adversely sensitive to the amplitude and form of geometric imperfections in the wall (Koiter, 1945; 1963; Yamaki, 1984; Rotter, 1998; 2004). Conversely, the internal pressure and the tensile circumferential membrane stress resultant both tend to a constant asymptotic value at some large depth, so that the risk of bursting does not increase beyond a certain depth

The design buckling strength is almost universally expressed in the form $\alpha \sigma_{\mathrm{cr}}$ where $\alpha$ is a 'knock-down' factor $(0<\alpha \leq 1)$ which attempts to account for the detrimental effect of geometric imperfections and $\sigma_{\mathrm{cr}}$ is the 'classical elastic critical buckling stress' for the reference case of uniform axial compression. The EN 1993-1-6 (2007) standard enhances this relationship to allow the cylinder to benefit from the strengthening effect of internal pressure, but also ensures that the design is penalised 
Published in: Journal of Constructional Steel Research, 67(10), 1537-1544.

DOI: http://dx.doi.org/10.1016/j.jcsr.2011.03.028

if the pressure is too high. However, there are some important effects which are not yet included in the hand-design rules, notably the restraint provided by a thicker lower plate at the base of a wall strake (Rotter and Teng, 1989), collapse near a boundary (Rotter, 1998) or the stiffening effect of the elastic restraint provided by the stationary granular solid inside the silo (Rotter and Zhang, 1990; Knödel et al., 1995).

This paper presents a significant enhancement and development of two previous studies by the authors (Sadowski \& Rotter, 2010; 2011). In each of these, the authors investigated the behaviour of a single metal silo of different aspect ratio in the slender range designed explicitly for concentric discharge pressures according to the structural assessment of EN 1993-1-6 and EN 1993-4-1. These were both introductory studies and the first of their kind to investigate and compare the structural consequences of the EN 1991-4 concentric and eccentric discharge load definitions directly. They explored the mechanics of the complex behaviour under these load cases, but it was impossible to present the full findings due to the complexity of the phenomena involved. As a shared conclusion, it was found that the predicted buckling strength of the silo under concentric discharge pressures was higher than that prescribed by the EN standard by a factor of approximately two when analysed with a nonlinear finite element analysis. Although this finding suggests a highly conservative design procedure, it is unsafe to assume that this will always be the case until silos of different aspect ratios have been studied. This is because the aspect ratio plays an vital role in both the behaviour and design of silos, and a finding for one aspect ratio is often not transferable to another.

The aim of this paper is to investigate the validity of the conservatism of the design process for metal silos of different aspect ratio, and to give a deeper insight into the associated behaviour which could not be seen in the authors' earlier papers. Since EN 1991-4 makes very substantial distinctions between silos of different aspect ratio, it is not safe to conclude that the above finding for a single structure is truly representative of all aspect ratios. This is particularly evident when it is recognised that slender silos are subject to a relatively low internal pressure but high axial compression, whilst squat silos on the contrary experience high internal pressure but rather small axial compression. This paper therefore explores the above discrepancy between the EN hand-design rules and a finite element prediction by investigating five custom- 
Published in: Journal of Constructional Steel Research, 67(10), 1537-1544.

DOI: http://dx.doi.org/10.1016/j.jcsr.2011.03.028

designed metal silos. The silos were chosen to have aspect ratios ranging from very squat to very slender in order to explore the range over which the finding of the previous study remains valid. Areas of the design process which may require modification are identified and discussed.

\section{Design of five example silos of different aspect ratio}

The European standard on actions on silos and tanks EN 1991-4 (2006) classifies silos solely on the basis of their aspect ratio (height over diameter, H/D). This is because the aspect ratio significantly influences the relative magnitudes and patterns of normal pressure $\left(p_{\mathrm{h}}\right)$ and frictional tractions $\left(p_{\mathrm{w}}\right)$ exerted by the stored granular solid on the silo wall (Eqs 1 to 3), and consequently also the structural behaviour of the silo. The classification criteria according to the silo aspect ratio defined by EN 1991-4 are presented in Table 1.

Table 1 - Summary of slenderness categories according to EN 1991-4 (2006)

\begin{tabular}{|c|c|c|}
\hline $\begin{array}{c}\text { Aspect ratio } \\
\text { range }\end{array}$ & $\begin{array}{c}\text { Axisymmetric } \\
\text { pressure distribution }\end{array}$ & $\begin{array}{c}\text { Silo slenderness } \\
\text { category }\end{array}$ \\
\hline$H / D \geq 2.0$ & Janssen & Slender \\
\hline $1.0<H / D<2.0$ & Modified Reimbert & Intermediate slender \\
\hline $0.4<H / D \leq 1.0$ & Modified Reimbert & Squat \\
\hline$H / D \leq 0.4$ & Geostatic & Retaining silo (flat bottom) \\
\hline
\end{tabular}

$\operatorname{Janssen}(H / D \geq 2.0): p_{h}(z)=p_{h 0}\left(1-e^{-z / z_{0}}\right)$

Modified Reimbert $(0.4<H / D<2.0): p_{h}(z)=p_{h 0}\left(1-\left\{\left(\frac{z-h_{0}}{z_{0}-h_{0}}\right)+1\right\}^{n}\right)$

Geostatic $(H / D \leq 0.4): p_{h}(z)=K \gamma z\left(1+\sin \phi_{r}\right)$

where $z_{0}=\frac{R}{2 \mu K}, p_{h 0}=K \gamma z_{0}$ and $n=-\left(1+\tan \phi_{r}\right)\left(1-\frac{h_{0}}{z_{0}}\right) . R$ is the silo radius, $K$ and $\mu$ are the lateral pressure ratio and the fully-developed wall friction coefficient between the granular solid and the wall respectively, $\gamma$ and $\phi_{r}$ are the unit weight and angle of repose of the granular solid respectively and $h_{0}$ is the height between the 
Published in: Journal of Constructional Steel Research, 67(10), 1537-1544.

DOI: http://dx.doi.org/10.1016/j.jcsr.2011.03.028

equivalent surface of the solid and the highest solid to wall contact. The associated frictional tractions are defined according to the usual relation $p_{\mathrm{w}}=\mu p_{\mathrm{h}}$.

For the purposes of this study, five steel silos were designed with different aspect ratios in the range $0.65 \leq H / D \leq 5.20$ and stepwise-varying wall thickness, in a manner similar to Sadowski \& Rotter $(2010 ; 2011)$. The designs were made to support the symmetrical loads arising from the storage of approximately $510 \mathrm{~m}^{3}$ of a generic material whose properties may be considered to be similar to those of wheat, which are representative of a wide range of different granular solids. The properties of the material were therefore taken from Annex E of EN 1991-4 as those of wheat, assuming fully-developed wall friction properties for a D2 'smooth' wall.

Table 2 - Summary of the parameters of the five example silos

\begin{tabular}{|c|c|c|c|c|c|c|c|c|}
\hline $\begin{array}{c}\text { Design silo name } \\
\text { Acronym) }\end{array}$ & $\begin{array}{c}H \\
(\mathrm{~m})\end{array}$ & $\begin{array}{c}D \\
(\mathrm{~m})\end{array}$ & $H / D$ & $\begin{array}{c}\text { Storage } \\
\text { volume } \\
\left(\mathrm{m}^{3}\right)\end{array}$ & $\begin{array}{c}\text { Steel } \\
\text { volume } \\
\left(\mathrm{m}^{3}\right)\end{array}$ & $\begin{array}{c}\text { Rating } \dagger \\
\text { capacity } \\
(\mathrm{t})\end{array}$ & $\begin{array}{c}\text { Loading } \dagger \\
\text { capacity } \\
(\mathrm{t})\end{array}$ & $\begin{array}{c}\text { Pressure } \\
\text { distribution }\end{array}$ \\
\hline Very Slender (VS) & 26.0 & 5.0 & 5.20 & 510.5 & 1.91 & 390.3 & 468.4 & Janssen \\
\hline Slender (S) & 18.0 & 6.0 & 3.00 & 508.9 & 1.41 & 389.1 & 466.9 & Janssen \\
\hline Boundary (B) & 14.0 & 6.8 & 2.06 & 508.4 & 1.12 & 388.7 & 466.5 & Janssen \\
\hline Intermediate (I) & 11.2 & 7.6 & 1.47 & 508.1 & 0.89 & 388.4 & 466.1 & Mod. Reimbert \\
\hline Squat (Q) & 6.5 & 10.0 & 0.65 & 510.5 & 0.32 & 390.3 & 468.4 & Mod. Reimbert \\
\hline
\end{tabular}

Note $(\dagger)$ : the lower characteristic value of the unit weight of the solid is used for rating the capacity of the silo to determine the Action Assessment Class; the higher characteristic value is used to calculate the actions on the silo (EN 1991-4, 2006:

Annex E).

The silos were assumed to be flat-bottomed with no hopper. The aspect ratios were chosen so that the volume and capacity of each silo was approximately equal whilst maintaining simple overall dimensions. As a result, each such silo of different aspect ratio may be considered to be a plausible alternative design to the same storage requirement and is analysed in this wider context, as opposed to Sadowski \& Rotter (2010; 2011) where only two slender silos $(H / D>2)$ were studied in total. The key parameters of each silo design are summarised in Table 2. For ease of identification, 
Published in: Journal of Constructional Steel Research, 67(10), 1537-1544.

DOI: http://dx.doi.org/10.1016/j.jcsr.2011.03.028

each silo was assigned a name and an acronym reflecting its slenderness category according to EN 1991-4 (see Table 1). The material properties for mild steel were assumed as: yield stress $=250 \mathrm{MPa}$, Poisson's ratio $=0.3$ and elastic modulus $=200$ GPa. A preliminary investigation of Silo $\mathrm{S}(H / D=3)$ on its own was previously presented in Sadowski \& Rotter (2010).

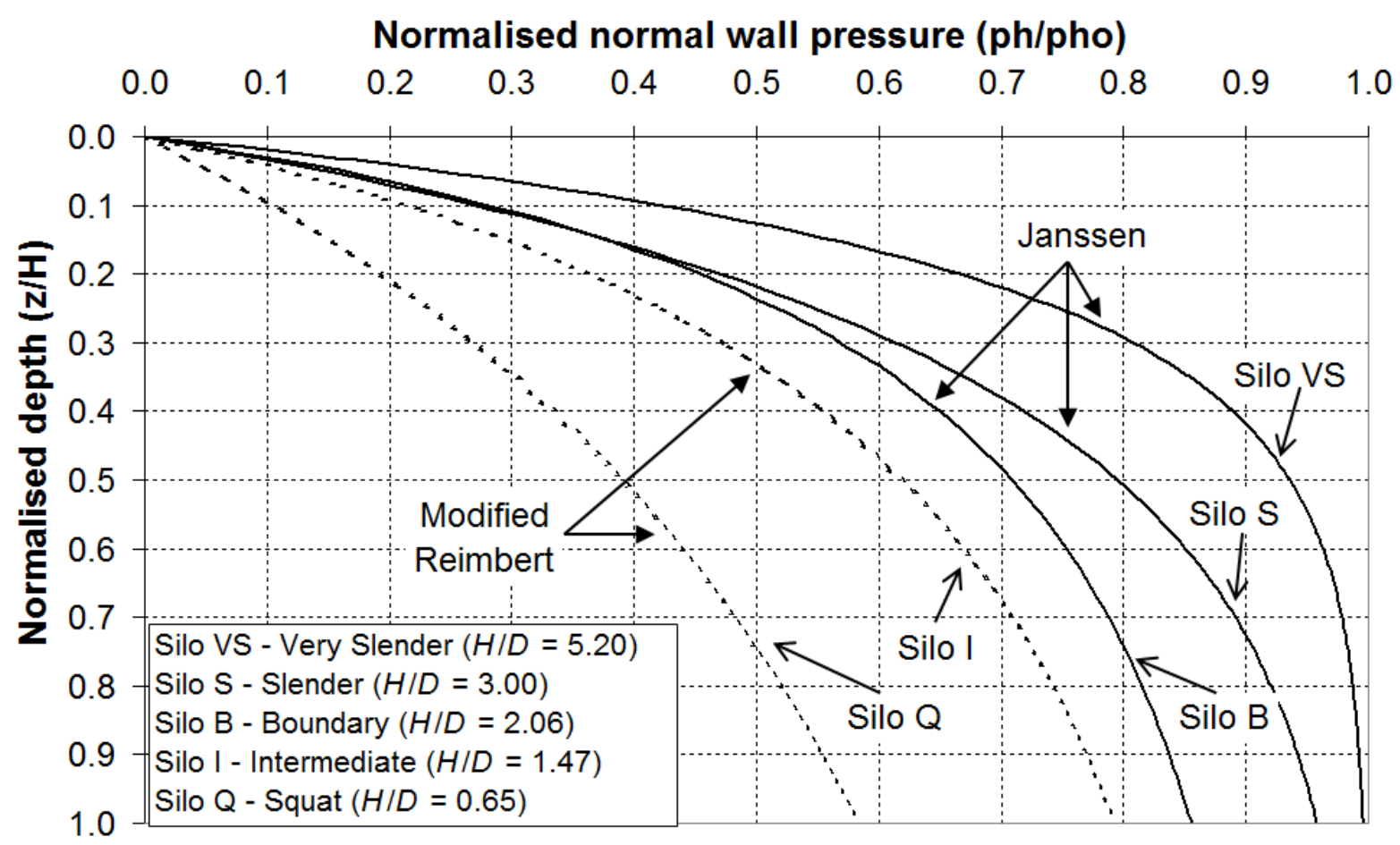

Fig. 1 - Axial distribution of normalised normal pressures for each silo design under concentric discharge, assuming the maximum pressure case for bursting

The structural design was carried out according to EN 1993-1-6 (2007) and EN 19934-1 (2007), using the concentric discharge pressures from EN 1991-4 (2006) under the maximum friction load case, which is the critical case for buckling under axial compression (Fig. 1). Action Assessment Class 2 was assumed based on the rated capacity and no filling or discharge eccentricity. The requirement for an unsymmetrical patch load was omitted to clarify the interpretation of the calculations. The EN 1991-4 discharge factors for normal pressures and frictional tractions, $C_{\mathrm{h}}$ and $C_{\mathrm{w}}$, were taken as 1.15 and 1.1 respectively for every silo design (including Silo Q) to be consistent, though EN 1991-4 does not require discharge factors for squat silos. The partial safety factor for unfavourable structural actions and the resistance partial safety factor for stability, $\gamma_{\mathrm{F}}$ and $\gamma_{\mathrm{M} 1}$, were taken as 1.5 and 1.1 respectively (EN 1993- 
Published in: Journal of Constructional Steel Research, 67(10), 1537-1544.

DOI: http://dx.doi.org/10.1016/j.jcsr.2011.03.028

$4-1,2007)$, giving an overall safety factor of $1.5 \times 1.1=1.65$ for the hand design calculations. This assumed value (1.65) will be compared with the computed load proportionality factor from a finite element calculation to obtain a realistic measure of the actual margin of safety of the designed structure.

In EN 1993-1-6, the effects of geometric imperfections are accounted for by a 'knockdown' factor $\alpha$ for buckling. This factor is modified to account for the effect of internal pressure, which can be either beneficial elastic stabilisation and detrimental plastic destabilisation, depending on the relative magnitude of the local internal pressure. For all silos, regardless of aspect ratio, the internal pressure was found to be beneficial to the buckling strength of the local wall strake, reducing the detrimental effect of imperfections and allowing $\alpha=\alpha_{\text {pe }}$ to be used in design (Eq. 4). Note that EN 1993-1-6 requires that $\alpha_{\mathrm{pe}}$ be calculated using the 'smallest design value of local internal pressure that can be guaranteed to coexist with the meridional compression', which in the present context means unfactored filling pressures (EN 1991-4, 2006). Consequently, finite element analyses which use the higher factored discharge pressures will inevitably predict a higher strength gain due to internal pressure than that which can be assumed in the hand-design procedure. This is a discrepancy in the EN 1993-4-1 standard which needs to be addressed.

$\alpha_{p e}=\alpha_{0}+\left(1-\alpha_{0}\right)\left[\frac{\bar{p}}{\bar{p}+0.3 \alpha_{0}^{-0.5}}\right]$

where $\bar{p}=\frac{p_{\text {filling }} R}{\sigma_{c r} t}, \frac{\Delta w_{k}}{t}=\frac{1}{Q} \sqrt{\frac{R}{t}}$ and $\alpha_{0}$ is the unpressurised imperfection reduction factor $\left(\alpha_{\mathrm{pe}}>\alpha_{0}\right)$, given by:

$$
\alpha_{0}=\frac{0.62}{1+1.91\left(\Delta w_{k} / t\right)^{1.44}}
$$

In the above, $\sigma_{\mathrm{cr}}$ is the classical elastic critical buckling stress $(\approx 0.605 E t / R)$ and $\Delta w_{\mathrm{k}}$ is the characteristic imperfection amplitude, taken as the hand-design value from EN 1993-1-6 (2007) Annex D for Fabrication Tolerance Quality Class C (see Table 3). The strength reduction caused by an imperfection depends on its amplitude relative to the local wall thickness $(\delta / t)$, but the prescribed imperfection amplitudes of EN 19931-6 are larger as the radius to thickness $(R / t)$ ratio increases. As a result, the thin upper 
Published in: Journal of Constructional Steel Research, 67(10), 1537-1544.

DOI: http://dx.doi.org/10.1016/j.jcsr.2011.03.028

strakes in each silo design have larger defined imperfections relative to the wall thickness (Table 3), though they are smaller in absolute geometric terms.

Table 3 - Summary of characteristic imperfection amplitudes to be used in handbased design (EN 1993-1-6, 2007; Annex D), adopted here in all analyses

\begin{tabular}{|c|c|c|c|c|c|}
\hline \multirow{2}{*}{$\begin{array}{c}\text { Wall } \\
\text { thickness } \\
(\mathrm{mm})\end{array}$} & \multicolumn{5}{|c|}{$\Delta w_{\mathrm{k}}$, units of local wall thickness } \\
\hline & $\begin{array}{c}\text { Silo VS } \\
(H / D= \\
5.20)\end{array}$ & $\begin{array}{c}\text { Silo } \mathrm{S} \\
(H / D= \\
3.00)\end{array}$ & $\begin{array}{c}\text { Silo B } \\
(H / D= \\
2.06)\end{array}$ & $\begin{array}{c}\text { Silo I } \\
(H / D= \\
1.47)\end{array}$ & $\begin{array}{c}\text { Silo Q } \\
(H / D= \\
0.65)\end{array}$ \\
\hline 1 & - & - & - & - & 4.419 \\
\hline 2 & - & - & - & - & 3.125 \\
\hline 3 & 1.804 & 1.976 & 2.104 & 2.224 & 2.552 \\
\hline 4 & 1.563 & 1.712 & 1.822 & 1.926 & - \\
\hline 5 & 1.398 & 1.531 & 1.630 & 1.723 & - \\
\hline 6 & 1.276 & 1.398 & 1.488 & - & - \\
\hline 7 & 1.181 & - & - & - & - \\
\hline
\end{tabular}

Silos with higher aspect ratios require significantly thicker walls than squatter silos because friction between the solid and the silo wall develops very high axial compression throughout the entire height of the silo, which is furthermore cumulative with depth (Fig. 2). Conversely, the circumferential membrane tension caused by normal pressure which tends towards a constant asymptotic value ( $p_{\mathrm{h} 0}$, Fig. 1$)$. The walls of each silo were made just thick enough at the base of each strake to meet the design requirements with respect to buckling, regardless of practical steel sheet sizes. The points at which the plate thickness changes consequently all become equally critical locations for buckling under the axisymmetric loading conditions (Fig. 2), so the numerical analyses which follow might therefore be expected to identify many buckling modes at different points with very similar load factors. Note that the wall thicknesses required to withstand buckling failure were always found to be far greater than those required to withstand simple bursting by rupture (Fig. 3), though this difference was smaller for squatter silos where the axial compression was much lower. Thus buckling considerations play a very important role in the design of silos of all aspect ratios. Lastly, the relative slenderness $\lambda$ according to EN 1993-1-6 (the square root of the ratio of plastic collapse load to critical elastic buckling stress) was 
Published in: Journal of Constructional Steel Research, 67(10), 1537-1544.

DOI: http://dx.doi.org/10.1016/j.jcsr.2011.03.028

always found to be above the plastic limit relative slenderness $\lambda_{\mathrm{p}}$, so that the handdesign procedure actually predicted elastic buckling for all silos.

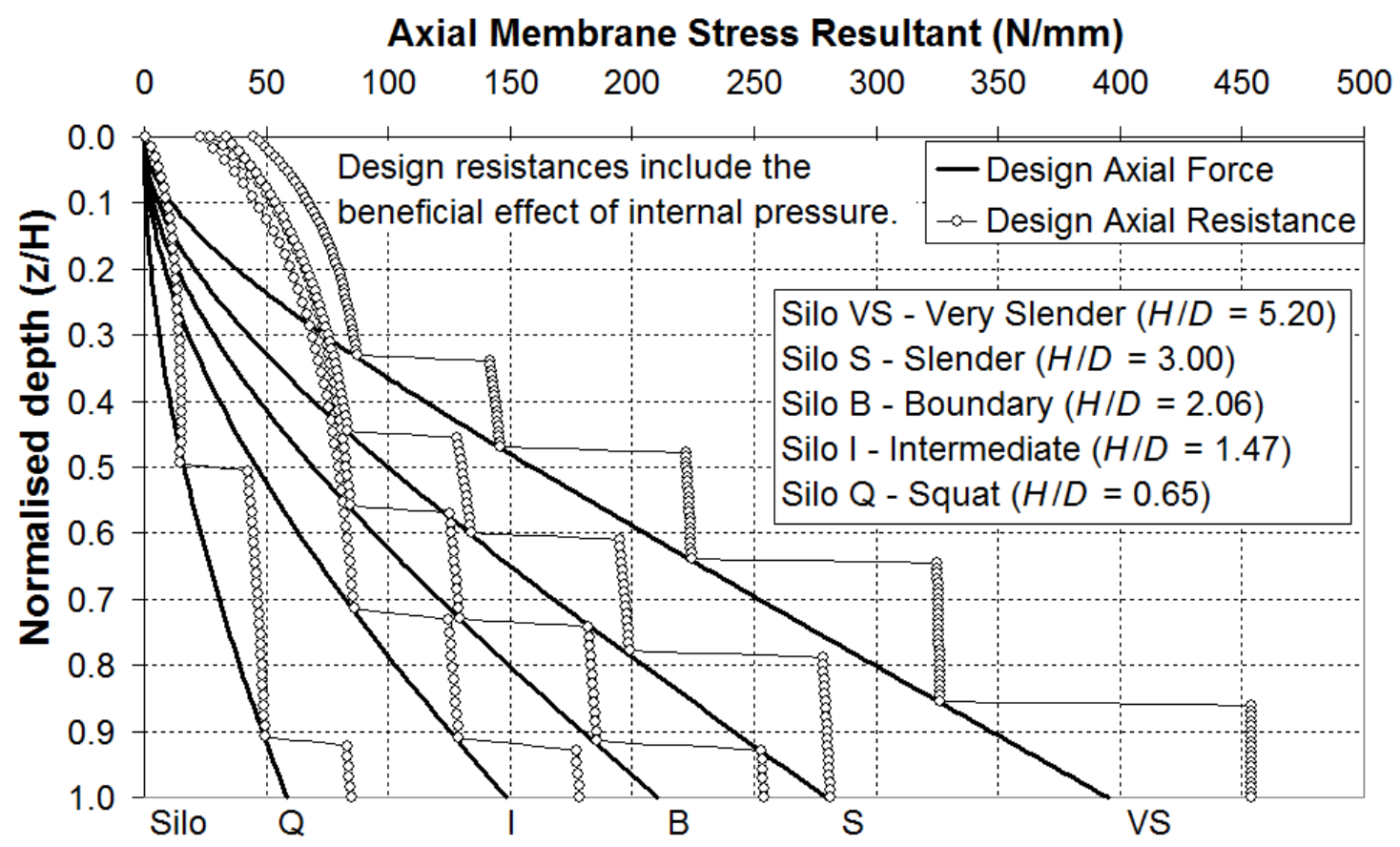

Fig. 2 - Axial distribution of the design (compressive) axial membrane stress resultants and design resistances for each example silo

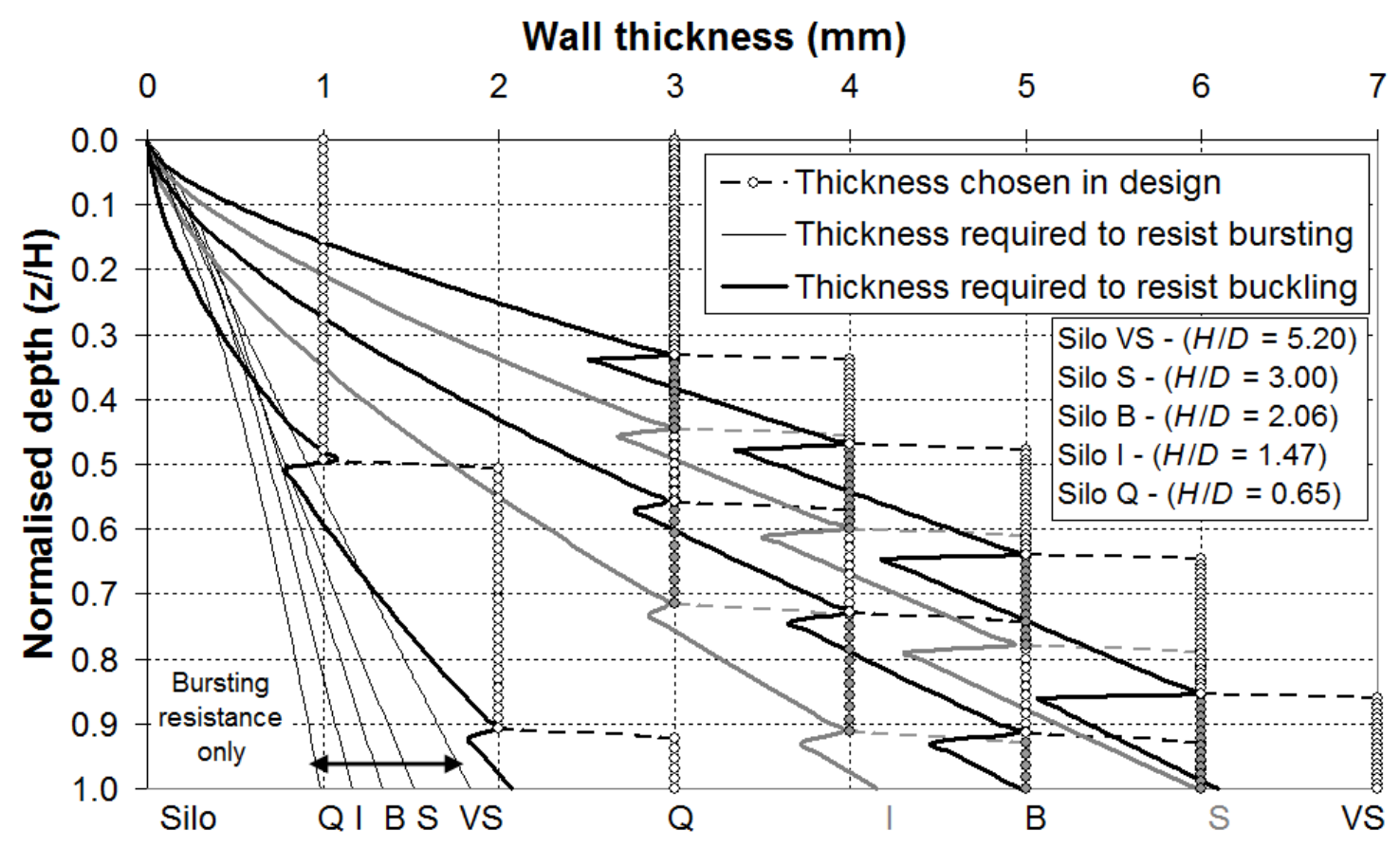

Fig. 3 - Axial distribution of required design thicknesses to resist bursting and buckling for each example silo 
Published in: Journal of Constructional Steel Research, 67(10), 1537-1544.

DOI: http://dx.doi.org/10.1016/j.jcsr.2011.03.028

The five silos are summarised schematically in Fig. 4, allowing a direct comparison between their geometries and wall strake thickness distributions. The squat Silo Q is unusual in that it was designed with a wall thickness of $1 \mathrm{~mm}$ for much of its height $(R / t=5000)$, which is at the very limit of what may be practicably possible to construct. Nonetheless, this theoretical thickness satisfies the required design rules, and it was therefore adopted for the purposes of this study. Furthermore, it was found that the required steel volume follows an approximately linear variation with the aspect ratio (Fig. 5). Since each one of the five silos is an alternative design for the same storage requirement, it is clear that flat-bottomed squat silos can provide a very economic solution for mass storage, provided other factors such as the footprint and fabrication costs do not override this consideration.

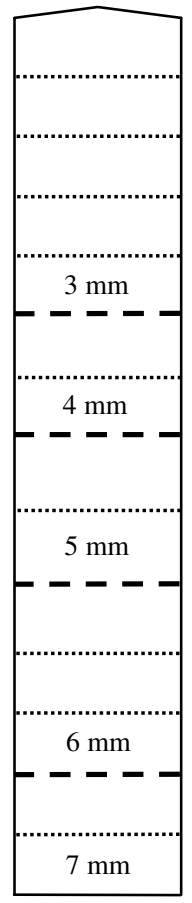

$\mathrm{VS}$

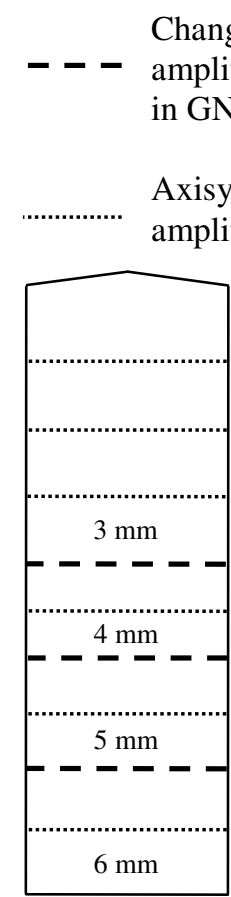

$\mathrm{S}$

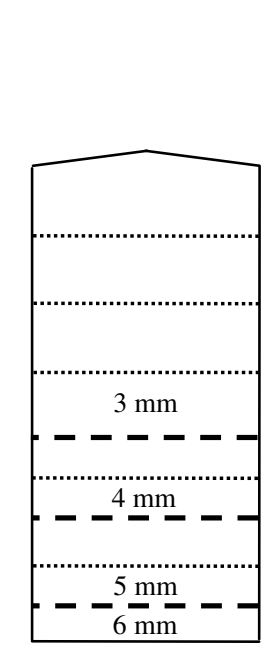

$\mathrm{B}$

$567 \leq R / t \leq 1133$

$357 \leq R / t \leq 833 \quad 500 \leq R / t \leq 1000$

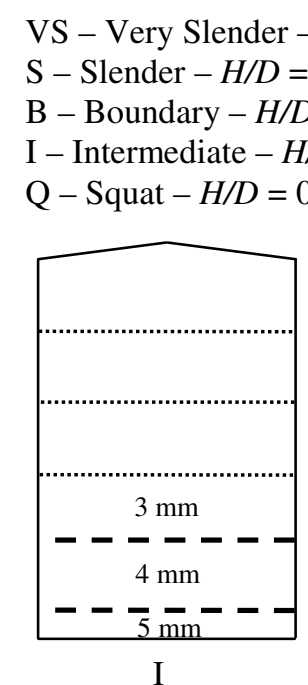

$760 \leq R / t \leq 1267$

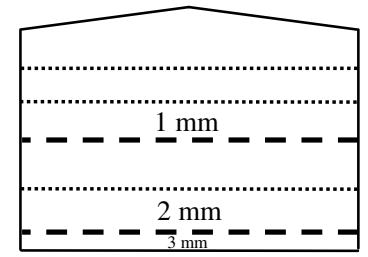

$\mathrm{Q}$

Fig. 4 - Schematics of the five silo designs with locations of imperfections and $R / t$ ranges, drawn to scale 
Published in: Journal of Constructional Steel Research, 67(10), 1537-1544.

DOI: http://dx.doi.org/10.1016/j.jcsr.2011.03.028

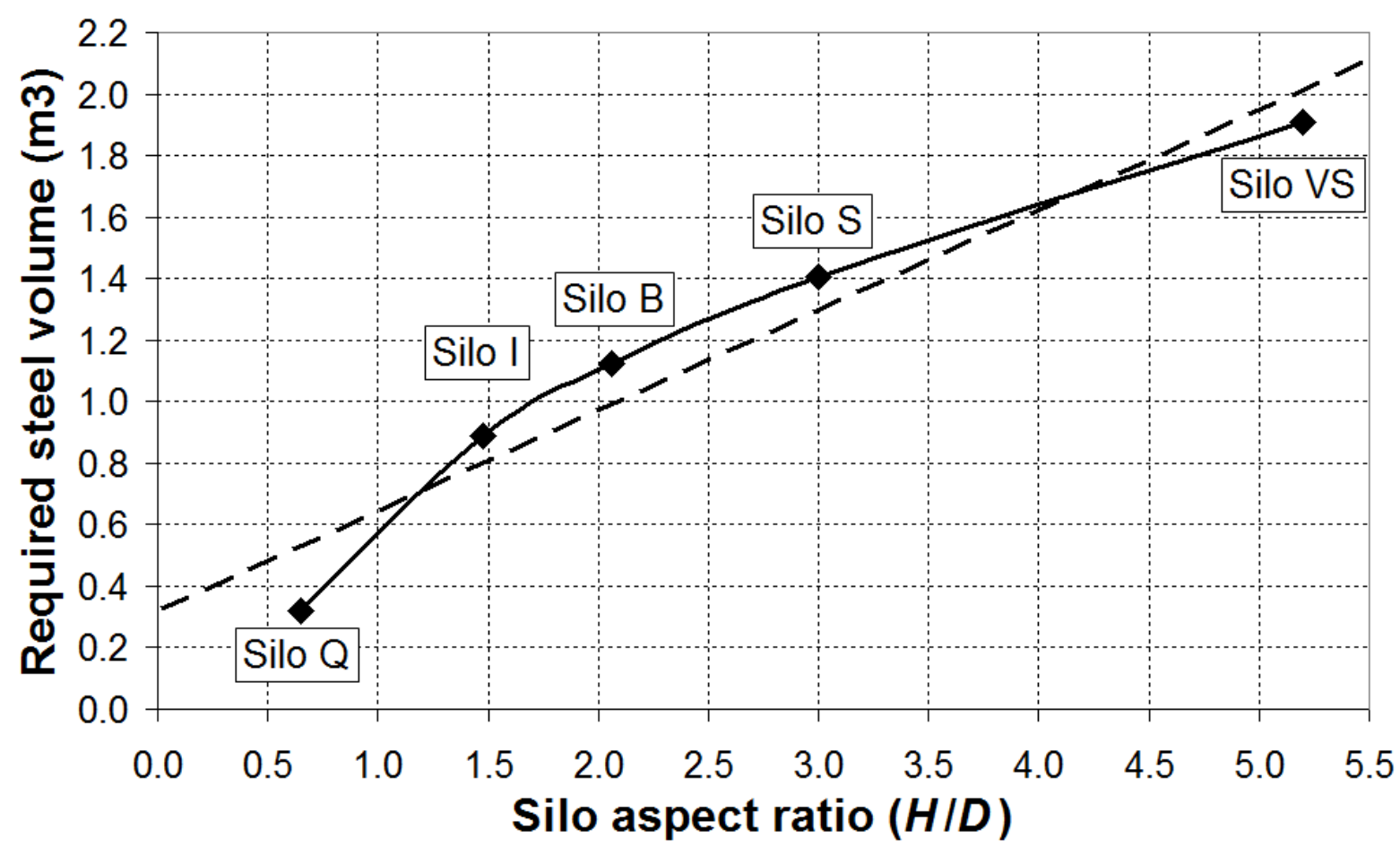

Fig. 5 - Variation of the required steel volume with aspect ratio for the silo cylinder

\section{Numerical analysis}

The example silos were modelled using the commercial finite element package ABAQUS (2009) under the concentric discharge condition. Using appropriate boundary conditions, only a quarter of the silo was modelled with nine-node reducedintegration S9R5 shell elements. The mesh resolution was increased near changes of plate thickness, at locations of weld imperfections and at the bottom pinned boundary. The top boundary consisted of a conical roof of inclination $15^{\circ}$ to the horizontal which was modelled using four-node S4R5 shell elements for each silo. The significance of modelling the roof as a boundary condition is made clear in the companion paper on eccentric discharge. When analysing the imperfect shell, axisymmetric weld depressions of Type A (Rotter and Teng, 1989) were introduced at several locations on each silo, including at every change of plate thickness (Fig. 4). The imperfection amplitude was always chosen as that of the hand design calculations ( $\Delta w_{\mathrm{k}}$, see Table 3). The same material properties for mild steel were used. 
Published in: Journal of Constructional Steel Research, 67(10), 1537-1544.

DOI: http://dx.doi.org/10.1016/j.jcsr.2011.03.028

\section{Nonlinear load-deflection behaviour}

The complete set of alternative computational shell calculations according to EN 1993-1-6 (2007) was performed on each silo, summarised in Table 4. Where applicable, the load-deflection path of a node on the silo-roof boundary was followed with the modified Riks (1979) procedure.

Table 4 - Summary of EN 1993-1-6 (2007) computational analyses used in this study

\begin{tabular}{|c|c|c|c|c|}
\hline $\begin{array}{c}\text { Analysis } \\
\text { acronym }\end{array}$ & Geometry & $\begin{array}{c}\text { Material } \\
\text { relation }\end{array}$ & $\begin{array}{c}\text { Presence of } \\
\text { imperfections }\end{array}$ & Objective of analysis \\
\hline LA & Linear & Linear & No & Reference linear-elastic stresses \\
\hline LBA & Linear & Linear & No & First buckling eigenvalue \& mode \\
\hline MNA & Linear & Nonlinear & No & Reference plastic collapse load \\
\hline GNA & Nonlinear & Linear & No & Lowest buckling load \& mode \\
\hline GMNA & Nonlinear & Nonlinear & No & Lowest buckling load \& mode \\
\hline GNIA & Nonlinear & Linear & Yes & Lowest buckling load \& mode \\
\hline GMNIA & Nonlinear & Nonlinear & Yes & Lowest buckling load \& mode \\
\hline
\end{tabular}

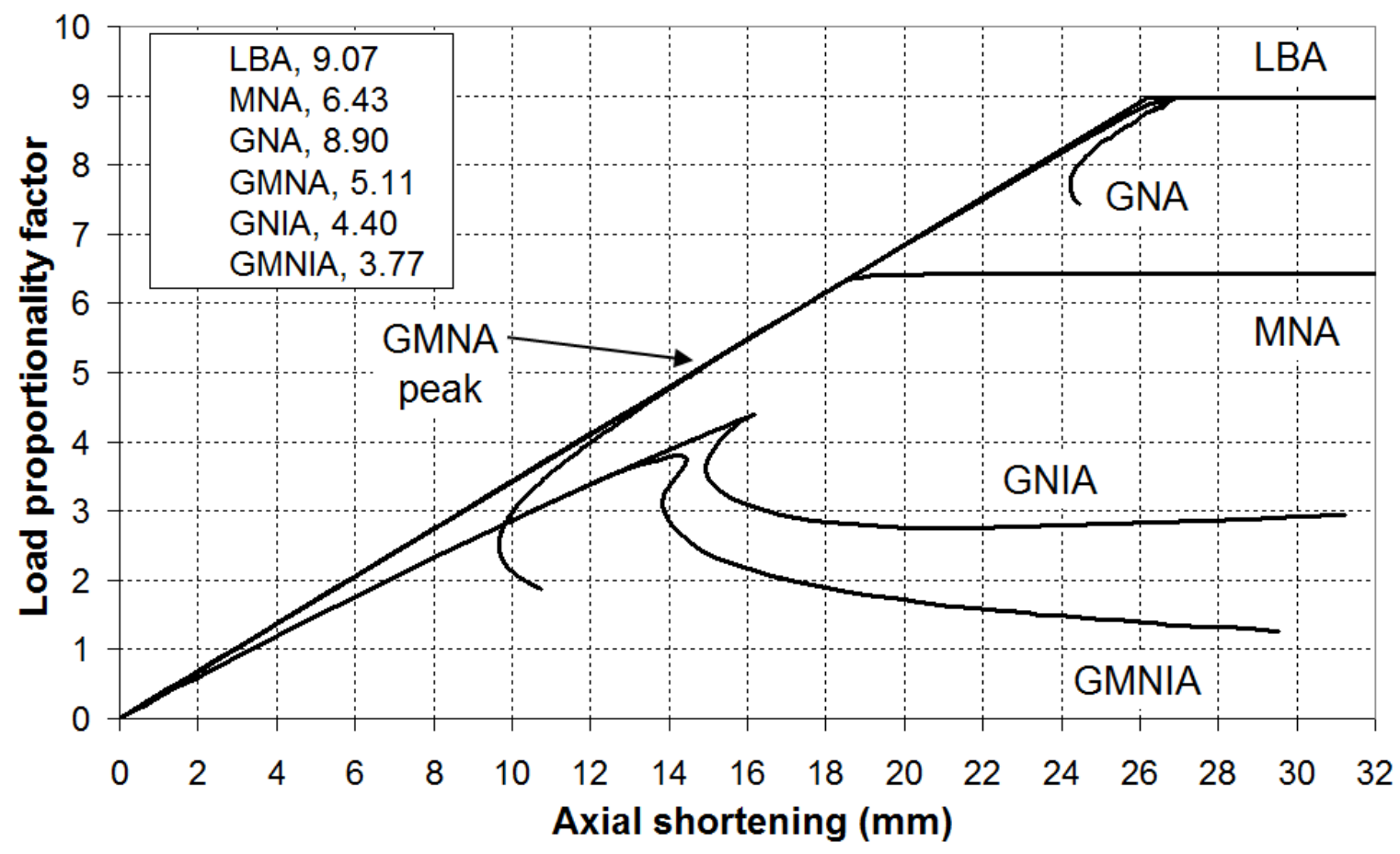

Fig. 6 - Load-deflection paths for Silo VS under concentric discharge showing unstable post-buckling behaviour, typical of shells under axisymmetric loads 
Published in: Journal of Constructional Steel Research, 67(10), 1537-1544.

DOI: http://dx.doi.org/10.1016/j.jcsr.2011.03.028

The nonlinear load-deflection paths for the very slender Silo VS are shown in Fig. 6 and clearly illustrate the differences between the different analyses. Specifically, the figure shows that the GNA-based analyses predict dramatic bifurcation buckling followed by a reversal of the equilibrium path, with a noticeable loss of linear stiffness when axisymmetric weld depressions are included. The remaining four silos all exhibited very similar nonlinear load-deflection paths under concentric discharge, for which the same observations can be made. In all cases, the inclusion of either geometric nonlinearity, material plasticity or imperfections resulted in progressively increased strength reductions. These reductions were found to be greatest for the slender silos.

\section{Predicted failure modes}

The example silos were designed to ensure that the base of each wall strake was critical for buckling under axisymmetric loading (Fig. 2). Consequently, it may be expected that multiple locations may become simultaneously critical, and as a result there will be a wide scatter of failure modes at different locations. However, EN 1993-1-6 only requires the analyst to determine the failure mode corresponding to the lowest load factor, which does not allow for the possibility of detecting failure at a different critical location if it occurs at only a slightly higher load factor.

Each of the load factors for the six EN 1993-1-6 computational analyses types defined in Table 4 relates to a different mechanism of collapse, grouped here under the umbrella term 'failure mode'. Thus the LBA and MNA analyses respectively give the linear bifurcation mode and plastic collapse mechanism directly. The GNA-based analyses give the incremental buckling mode, in which the pre-buckling deformations are subtracted from the immediate post-buckling deformations at the buckling load factor to determine the incremental form (Sadowski \& Rotter, 2010).

The failure modes for the intermediate and very slender Silos I and VS are shown in Figs 7 and 8 respectively. The intermediate slender Silo I exhibits similar failure modes regardless of analysis type (Fig. 7). Thus the LBA, GNA and GNIA analyses show elastic axial compression buckling modes, the MNA analysis shows a bursting failure under circumferential tension, while the GMNA and GMNIA analyses both 
Published in: Journal of Constructional Steel Research, 67(10), 1537-1544.

DOI: http://dx.doi.org/10.1016/j.jcsr.2011.03.028

show an elastic-plastic elephant's foot buckling mode. In each of these analyses, failure is predicted to occur at the base of the thinnest $3 \mathrm{~mm}$ wall strake. The similarity of these failure modes reflects the fact that the range of load factors for Silo I is not very wide, varying from 5.55 to 3.09 for LBA to GMNIA respectively.
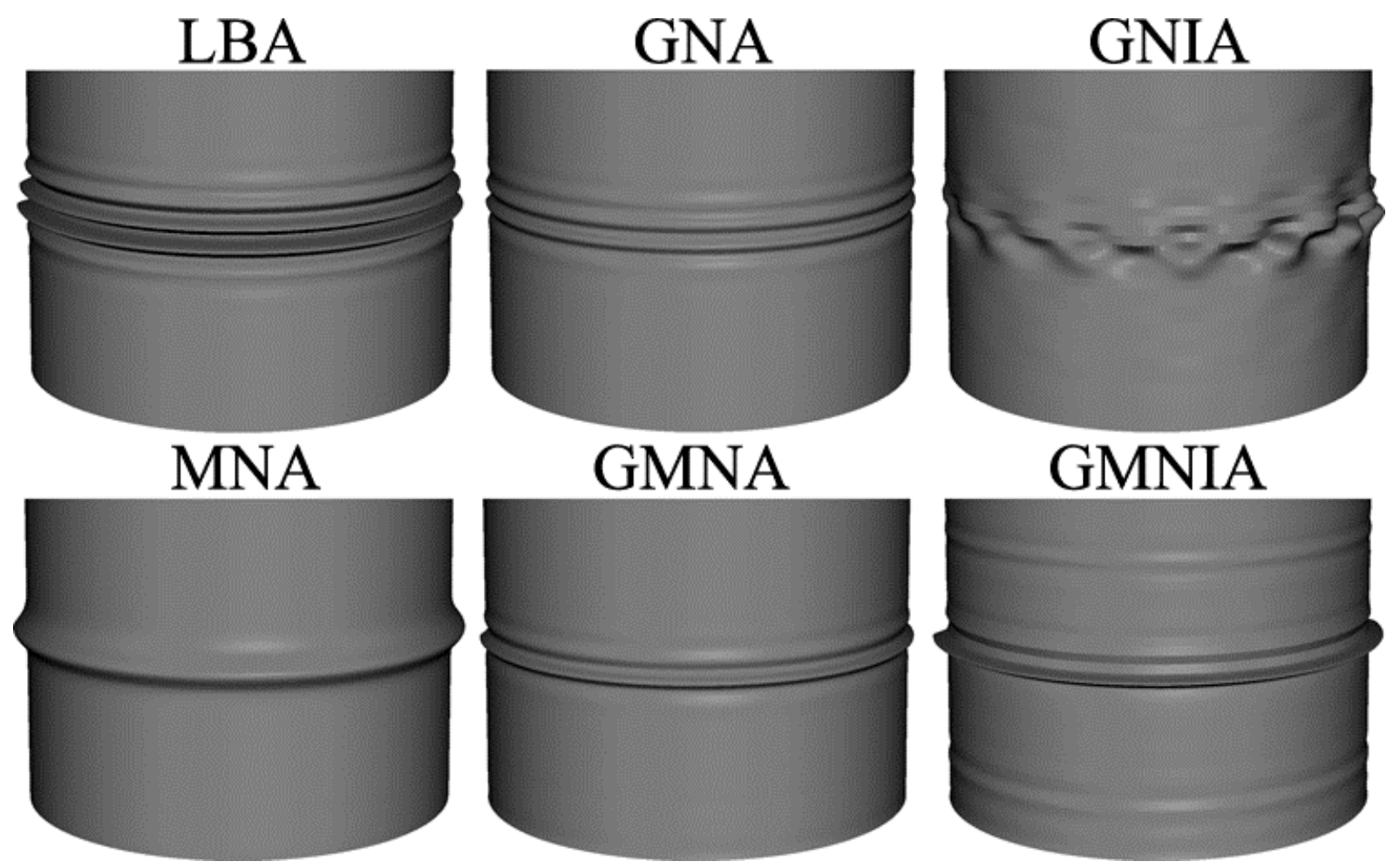

GMNIA

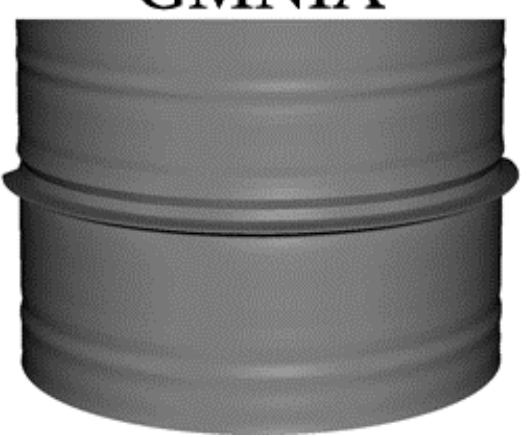

Fig. 7 - Failure modes for the rather squat Intermediate Silo I $(H / D=1.47)$,

characteristic of the squatter silos analysed in this study

By contrast, the very slender Silo VS exhibits a more varied set of failure modes (Fig. 8). The LBA and GNA analyses predict similar elastic axial compression buckling modes. However, the MNA analysis shows a yielding failure under the combination of circumferential tension and axial compression at the base of the silo, while the GMNA analysis shows a localised elastic-plastic elephant's foot buckle. The GNIA and GMNIA analyses show global diamond buckling modes with interesting signs of interactions between the adjacent weld depressions leading to a lower buckling strength (Rotter, 1996; Pircher and Bridge, 2000). The differing locations and character of these failure modes reflects the range of load factors from LBA to GMNIA, varying from 9.07 to 3.77 respectively for Silo VS. 
Published in: Journal of Constructional Steel Research, 67(10), 1537-1544.

DOI: http://dx.doi.org/10.1016/j.jcsr.2011.03.028
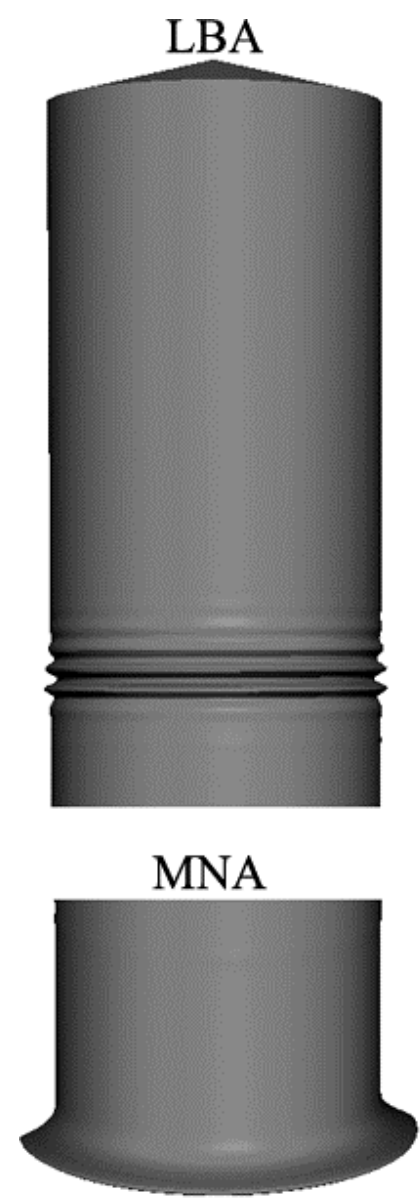
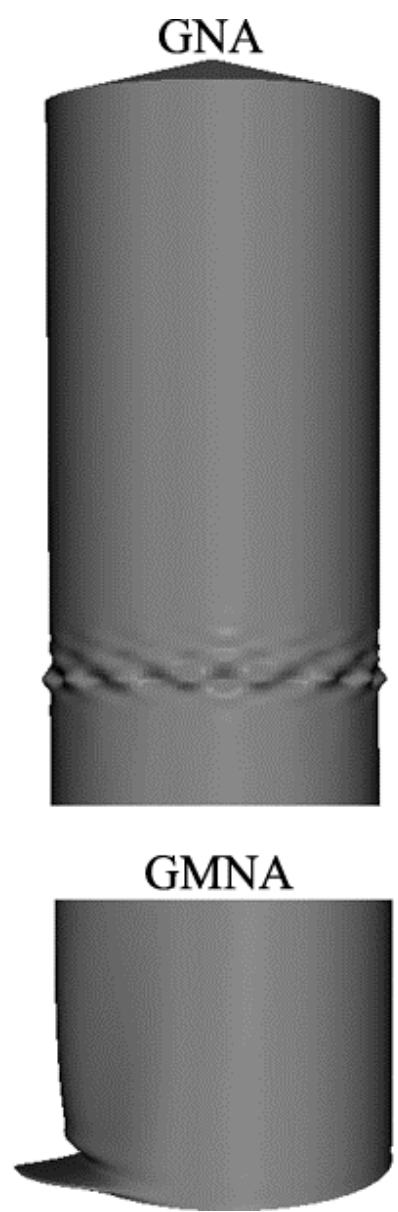

GNIA

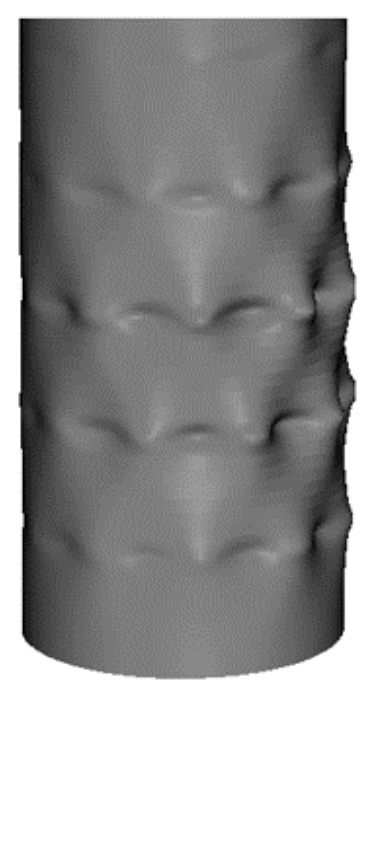

GMNIA

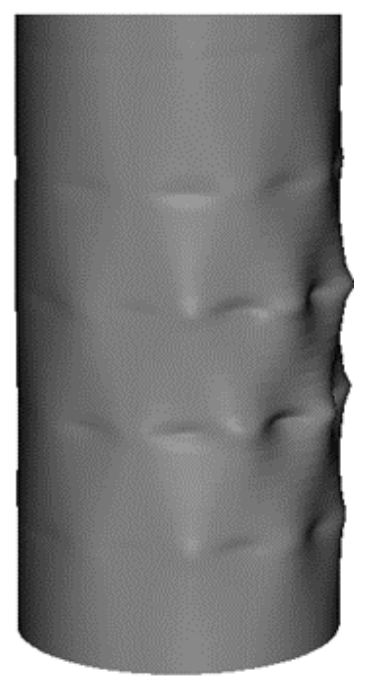

Fig. 8 - Failure modes for the Very Slender Silo VS $(H / D=5.20)$, characteristic of

the slender silos analysed in this study

The full set of failure modes is summarised schematically in Fig. 9. This figure shows that the squatter Silos I and Q, designed using the modified Reimbert discharge pressures, exhibit similar characteristics in terms of the types and locations of the failure modes. Similarly, the more slender Silos B, S and VS, designed using Janssen discharge pressures, exhibit a different but equally consistent set of characteristic failure modes. Thus both groups exhibit failure modes under concentric discharge that are representative of their particular class of aspect ratio (Table 1).

The failure modes identified here are, of course, simply those that occur at the lowest computed load factor, and no indication is available of their proximity to failure at another location. However, since each of the five silos was designed according to the EN 1993-1-6 and EN 1993-4-1 hand design procedure to make all strakes equally critical, some scatter in the most critical failure mode is entirely to be expected and 
Published in: Journal of Constructional Steel Research, 67(10), 1537-1544.

DOI: http://dx.doi.org/10.1016/j.jcsr.2011.03.028

supports the hand design rules as giving a relatively uniform safety factor throughout.

Consequently, it is not possible to read too much into the calculated failure locations.

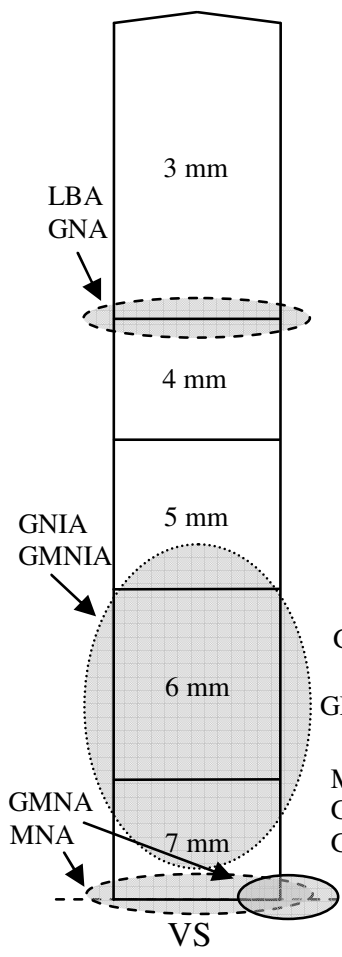

$$
\begin{aligned}
& \text { VS }- \text { Very Slender }-H / D=5.20 \\
& \mathrm{~S}-\text { Slender }-H / D=3.00 \\
& \mathrm{~B}-\text { Boundary }-H / D=2.06 \\
& \mathrm{I}-\text { Intermediate }-H / D=1.47 \\
& \mathrm{Q}-\text { Squat }-H / D=0.65
\end{aligned}
$$

Axisymmetric elastic buckle (LBA, GNA \& GNIA), plastic bursting mode (MNA) or elastic-plastic elephant's foot buckling mode (GMNA \& GMNIA), localised near a boundary.

Global diamond buckling mode spanning several wall strakes (GNIA \& GMNIA only).

Localised elastic-plastic elephant's foot buckling mode at a boundary (GMNA \& GMNIA only).

Fig. 9 - Summary schematic of predicted failure mode locations at the lowest load factor for the five silos analysed under concentric discharge, drawn to scale

\section{Analysis of load proportionality factors}

The computed EN 1993-1-6 load proportionality factors for the five example silos are summarised in Table 5 and plotted against the aspect ratio in Fig. 10. In all of the present analyses, the LBA and GNA predictions are very close, suggesting that the silo behaviour exhibits a high degree of linearity under concentric discharge. The MNA factors are well below those for LBA or GNA in the slender aspect ratio range, though the two sets of curves become closer to each other with decreasing aspect ratio and eventually intersect at approximately $H / D=1.5$. Thus slender silos under concentric discharge may be expected to exhibit predominantly plastic buckling behaviour, whilst squat silos are more likely to exhibit predominantly elastic buckling behaviour. This is confirmed by the relatively large drop in load factor from GNA to GMNA for slender silos, but not for squatter silos. Also, the GNIA and GMNIA load 
Published in: Journal of Constructional Steel Research, 67(10), 1537-1544.

DOI: http://dx.doi.org/10.1016/j.jcsr.2011.03.028

factors are always lower than all of the others, which shows that the axisymmetric weld imperfection is very deleterious to the predicted buckling strength, and may well be the most damaging realistic imperfection form for a silo for this load condition, as suggested by Rotter (2004).

Table 5 - Summary of the predicted load factors under concentric discharge

\begin{tabular}{|c|c|c|c|c|c|}
\hline Analysis & $\begin{array}{c}\text { Silo VS } \\
(H / D= \\
5.20)\end{array}$ & $\begin{array}{c}\text { Silo S } \\
(H / D= \\
3.00)\end{array}$ & $\begin{array}{c}\text { Silo B } \\
(H / D= \\
2.06)\end{array}$ & $\begin{array}{c}\text { Silo I } \\
(H / D= \\
1.47)\end{array}$ & $\begin{array}{c}\text { Silo Q } \\
(H / D= \\
0.65)\end{array}$ \\
\hline LBA & 9.07 & 7.85 & 6.97 & 5.55 & 1.79 \\
\hline MNA & 6.43 & 6.89 & 6.64 & 5.65 & 2.48 \\
\hline GNA & 8.90 & 7.77 & 6.93 & 5.55 & 1.76 \\
\hline GMNA & 5.11 & 4.91 & 5.55 & 4.70 & 1.60 \\
\hline GNIA & 4.40 & 5.62 & 4.55 & 4.57 & 1.58 \\
\hline GMNIA & 3.77 & 3.99 & 3.75 & 3.09 & 1.28 \\
\hline
\end{tabular}

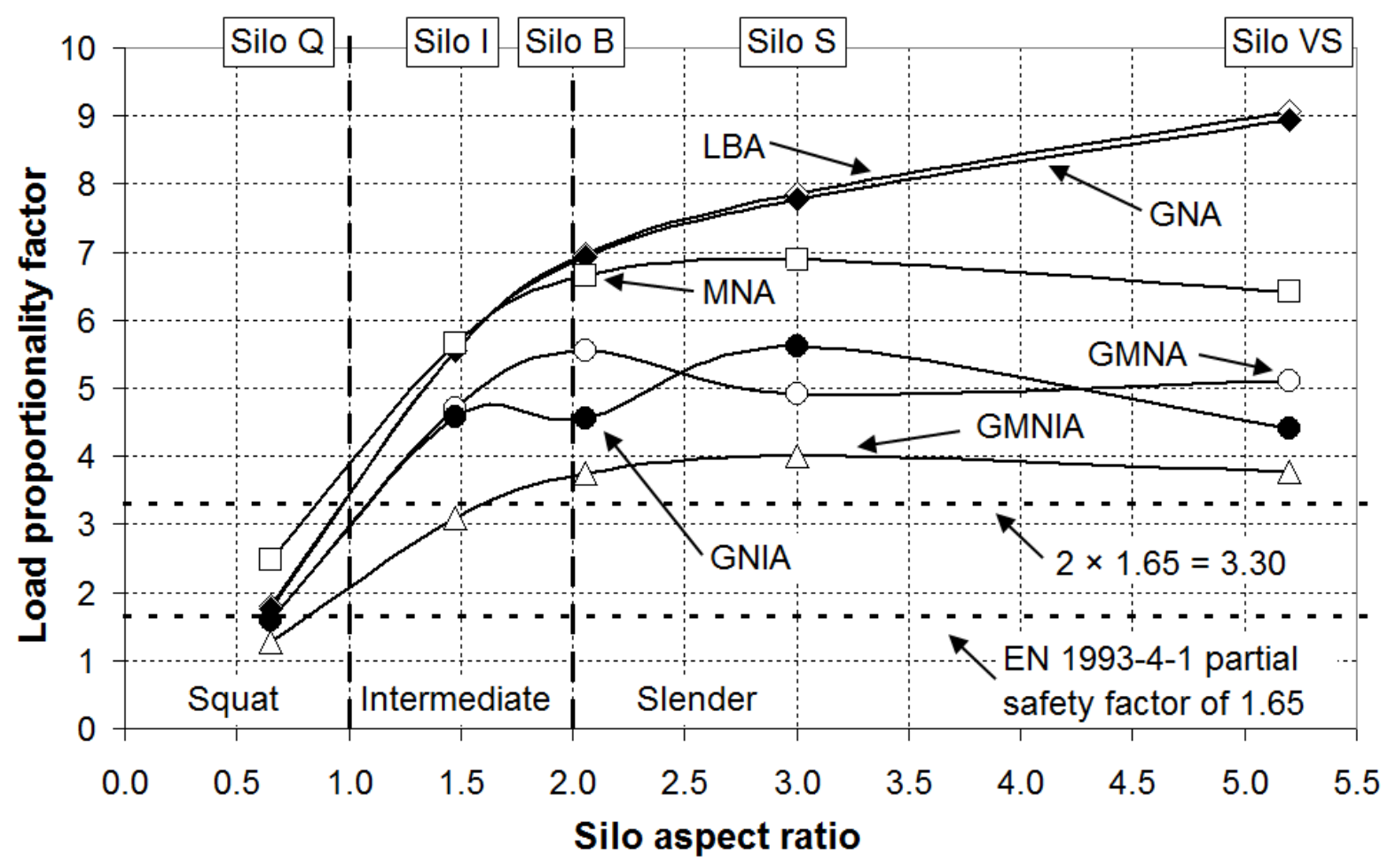

Fig. 10 - Plot of the load proportionality factors as a function of the silo aspect ratio

It is important that the shell analyst ascertains whether the failure mode will indeed be elastic or plastic, as this will influence the decision on whether to spend resources on 
Published in: Journal of Constructional Steel Research, 67(10), 1537-1544.

DOI: http://dx.doi.org/10.1016/j.jcsr.2011.03.028

a higher steel grade with a higher yield stress. Thus it may be worthwhile to invest in a stronger grade of steel for slender silos, which in this case would place the MNA curve above those of LBA or GNA, and equate the GNIA and GMNIA curves. However, for aspect ratios below approximately $H / D=1.5$, the use of higher practical grade of steel is unlikely to serve any purpose given the proximity of all load factors regardless of analysis type. The shell analyst may thus usefully explore different values of the yield stress when undertaking computational analyses that include material nonlinearity (i.e. MNA, GMNA and GMNIA) in order to fully understand the behaviour of the silo under concentric discharge, and to obtain an efficient and safe design.

It is surprising that material plasticity has been found to have any influence on the nonlinear buckling strengths of the silos analysed here, given that the design values of the relative slenderness $\lambda$ were in a range that predicted fully elastic buckling for each silo ( $\lambda>\lambda_{\mathrm{p}}$, where $\lambda_{\mathrm{p}}$ is the plastic limit relative slenderness). The EN 1993-1-6 standard defines the relative slenderness as $\lambda=\sqrt{ }$ (yield stress / elastic critical buckling stress), a formula which does not consider the influence of geometric imperfections or changes of plate thickness. Clearly, the silos analysed in this study have multiple locations at which deep circumferential weld depressions and/or changes of plate thickness are present causing substantial local axial bending and increased stresses. Since these locations have also been found to be critical for buckling, it is to be expected that the nonlinear finite element analyses predict elastic-plastic buckling, rather than just elastic as the EN hand-design procedure would suggest. This is clearly an important discrepancy which should be ratified, perhaps by making the relative slenderness $\lambda$ dependent on other parameters, such as imperfection amplitude.

\section{Critique of the conservatism of the design process}

In the analyses of Silos VS, S, B and I, the lowest GMNIA load factors were all found to be consistently close to or above 3.3 (Fig. 10), which is double the EN 1993-4-1 partial safety factor for hand design of 1.65. This significant reserve of strength is in part due to layers of conservatism and in part due to the empirical nature of the source data employed in the calibration of the EN 1993-1-6 elastic imperfection reduction 
Published in: Journal of Constructional Steel Research, 67(10), 1537-1544.

DOI: http://dx.doi.org/10.1016/j.jcsr.2011.03.028

factor $\alpha$ (Rotter, 1997; 1998; 2004). The main reasons for the substantial and consistent strength reserve are:

a) In Eq. 5, the expression for the unpressurised reduction factor $\alpha_{0}$ was derived as a lower bound empirical fit to a wide scatter of experimental data. The low value of 0.62 arises from a factor 0.83 in the basic strength formula due to Pflüger (1966) on which an additional safety factor of 0.75 was imposed by the ECCS Recommendations EDR4 (1988), so that $0.83 \times 0.75=0.62$. This rule implies that even the design buckling strength of a 'perfect' unpressurised shell is only allowed to be $62 \%$ of the classical elastic critical buckling stress $\sigma_{\mathrm{cr}}$.

b) In each of the silos analysed in this study, a common critical location is the base of the thinnest $3 \mathrm{~mm}$ strake (Fig. 9) where the relative change in strake thickness is highest (i.e. $4 / 3>5 / 4>6 / 5$ etc.). A thicker lower plate is known to provide additional restraint against buckling (Rotter and Teng, 1989), and as this the ratio of thicknesses rises, the strength gain increases. Similarly, the base boundary condition provides a restraint equivalent to an infinitely thick lower strake. The beneficial effects of such restraints are not included in the design process, further divorcing the numerical predictions from the EN hand-design safety factor.

c) A third aspect not addressed either by these calculations, the provisions of the shells standard EN 1993-1-6 or the ECCS Recommendations EDR5 (2008) is the imperfection form of non-uniform support of a shell at its boundary. Although this is included in EN 1993-1-6 as a tolerance criterion, it does not feature in the provisions for the computational assessment of imperfect shells (GMNIA). However, there is considerable evidence (Hoff and Soong, 1967; Ummenhofer et al., 1997; Greiner 2008) that a non-uniform support is a key cause of the low buckling strengths that have been found in experiments (Rotter, 2004).

These three aspects indicate that the considerable conservatism found in the calculations of the present study should be treated with caution until the same aspects of the simplifications used in the standards have been explored further. Nonetheless, these calculations show that the conservatism of the EN 1993-1-6 and EN 1993-4-1 standards is present for silos under axisymmetric loading across a very wide range of 
Published in: Journal of Constructional Steel Research, 67(10), 1537-1544.

DOI: http://dx.doi.org/10.1016/j.jcsr.2011.03.028

practical aspect ratios, and applies to both the buckling and plastic collapse failure modes. However, Silo Q provides an exception to the otherwise highly conservative design due to the very thin wall over most of its height. The final GMNIA value for Silo $\mathrm{Q}$ is 1.28 and falls troublingly below the strength assessment of 1.65 envisaged in

EN 1993-4-1. The design of Silo Q is unusual in that it has a rather low capacity for its aspect ratio $(H / D=0.65)$. Silos are usually designed as squat when they store very large volumes (Rotter, 2001), and consequently would have wall thicknesses significantly larger than $1 \mathrm{~mm}$. Thus the reduction of the GMNIA load factor for Silo $\mathrm{Q}$ below the partial safety factor of 1.65 may be explained by the fact that the relative change in wall thickness from 1 to $2 \mathrm{~mm}$ is $100 \%$, making the base of the $1 \mathrm{~mm}$ strake behave like a base boundary condition. The severity of this change is exacerbated by the deep weld depression at this location, with an amplitude of 4.419 local wall thicknesses (Table 3).

\section{Further considerations in silo design}

Whilst the calculations undertaken in this study have clearly shown that the hand design calculation process for metal silos under entirely symmetrical loads is very conservative compared with a finite element model for the same conditions, caution should be exercised in drawing very bold conclusions from it.

First, it should be noted that the pressures exerted by discharging solids, even under discharge conditions that appear to be concentric, have much more complicated patterns than are used in the standard (Ooi et al., 1990; Rotter 2008). Further, unsymmetrical pressures lead to disproportionately high axial membrane stresses (Rotter, 2006; Sadowski \& Rotter, 2010; 2011) which are at their most serious when a local drop in pressure occurs, rather than a local rise.

Second, because the pressure may locally drop below the design EN 1991-4 filling values during discharge (Rotter, 2008), it may be sometimes unconservative even to use the filling values of internal pressure when evaluating the buckling strength gains due to internal pressure (see Eq. 4). For finite element analysts who seek to use a consistent set of pressures in a simplified codified pattern, this presents an anomalous 
Published in: Journal of Constructional Steel Research, 67(10), 1537-1544.

DOI: http://dx.doi.org/10.1016/j.jcsr.2011.03.028

challenge. Amendments to the two standards EN 1991-4 and EN 1993-4-1 are needed to address this situation.

\section{Conclusions}

This paper has examined five example silos with aspect ratios in the range $0.65 \leq H / D$ $\leq$ 5.20. Each silo was designed according to the EN 1993-1-6 and EN 1993-4-1 hand design procedure under the EN 1994-1 concentric discharge loads. All but the squattest of the five silos were found to deliver very significant reserves of strength (as computed with a GMNIA analysis), by a factor of at least 2, beyond the intended safety factor of 1.65 .

The conservatism may be explained by the fact that the EN 1993-1-6 design rule for the buckling of an imperfect shell is calibrated against a lower bound fit to a wide scatter of experimental data, and subject to further safety factors not mentioned in the standard. These rules appear to give very low buckling strengths that are not obtainable in a nonlinear finite element analysis with imperfection amplitudes equal to those assumed in the standard.

An exception to this conservatism was found with the squattest silo of the group whose GMNIA load factor fell $22 \%$ below the EN partial safety factor of 1.65. Though designed strictly according to the appropriate procedure, this silo has a very thin $1 \mathrm{~mm}$ wall over much of its height, so that at the base of this strake there is a $100 \%$ increase in wall thickness from $1 \mathrm{~mm}$ to $2 \mathrm{~mm}$. This suggests that large changes in wall thickness actually result in very low load factors in squat silos.

A curious discrepancy arises due to the fact that material plasticity was found to have lead to reduced nonlinear buckling strengths in all geometrically nonlinear analyses, i.e. the GMNA and GMNIA load factors were always lower than the respective GNA and GNIA load factors. Though it is usual that numerical analyses predict elasticplastic buckling under axisymmetric conditions, especially where geometric discontinuities such as deep weld depressions or changes of wall thickness are present, the EN 1993-1-6 hand-design procedure had predicted fully elastic buckling in all cases. This is an important discrepancy which should be addressed. 
Published in: Journal of Constructional Steel Research, 67(10), 1537-1544.

DOI: http://dx.doi.org/10.1016/j.jcsr.2011.03.028

The putative excessive conservatism of the design process should, however, be treated with care. This is because pressure distributions in silos under seemingly concentric flow regimes are in reality far from axisymmetric, despite what the rather simplistic Janssen and modified Reimbert distributions that are used so widely in design would lead one to believe. The buckling strengths of thin-walled metal silos are particularly sensitive to unsymmetrical pressure patterns, hence even localised variations in normal pressure may have detrimental consequences, especially if a drop in pressure occurs.

\section{References}

ABAQUS (2009). “ABAQUS Version 6.9” Dassault Systèmes Simulia Corp., Providence, RI, USA.

ECCS EDR4 (1988). "European Recommendations for Steel Construction: Buckling of Shells, 4th edition.” European Convention for Constructional Steelwork, Brussels.

ECCS EDR5 (2008). "European Recommendations for Steel Construction: Buckling of Shells, 5th edition.” European Convention for Constructional Steelwork, Brussels.

EN 1991-4 (2006). "Eurocode 1: Actions on Structures, Part 4: Silos and Tanks." European Committee for Normalisation, Brussels.

EN 1993-1-6 (2007). "Eurocode 3: Design of Steel Structures, Part 1-6: Strength and Stability of Shell Structures." Comité Européen de Normalisation, Brussels.

EN 1993-4-1 (2007). "Eurocode 3: Design of Steel Structures, Part 4-1: Silos." Comité Européen de Normalisation, Brussels.

Greiner R. (2008). “Tolerance value of unevenness of foundation." Private communication to J.M. Rotter, Feb. 2008. 
Published in: Journal of Constructional Steel Research, 67(10), 1537-1544.

DOI: http://dx.doi.org/10.1016/j.jcsr.2011.03.028

Hoff N.J. \& Soong T.C. (1967). "Buckling of Axially-Compressed Cylindrical Shells with Non-Uniform Boundary Conditions." Symposium of Thin-Walled Structures, University College, Swansea, 61-80.

Knödel, P., Ummenhofer, T. \& Schulz, U. (1995). “On the Modelling of Different Types of Imperfections in Silo Shells.” Thin-Walled Structures, 23, 283-293.

Koiter W.T. (1945). "On the stability of elastic equilibrium." PhD Thesis, Delft University, Holland.

Koiter W.T. (1963). "The effect of axisymmetric imperfections on the buckling of cylindrical shells under axial compression." Proc. Kon. Ned. Akad. Wet., B66, 265279. (See also Appl. Mech. Rev., 18, Review 3387, 1965).

Ooi J.Y., Rotter J.M. \& Pham L. (1990). "Systematic and Random Features of Measured Pressures on Full-Scale Silo Walls.” Engineering Structures, 12(2), 74-87.

Pflüger A. (1966). "Zur praktischen Berechnung der Kreiszylinderschalen unter Manteldrück.” Der Stahlbau, 5(8), 249-252.

Pircher M. \& Bridge R.Q. (2000). "Buckling and post-buckling behaviour of silos and tanks under axial load - some new aspects.” Jrnl. of Struct. Eng., ASCE, 127(10), 1129-1136.

Riks E. (1979). "An incremental approach to the solution of snapping and buckling problems.” Int. J. of Solids and Structures, 15, 529-551.

Rotter J.M. (1996). "Elastic plastic buckling and collapse in internally pressurised axially compressed silo cylinders with measured axisymmetric imperfections: interactions between imperfections, residual stresses and collapse." Proc. Int. Workshop on Imperfections in Metal Silos: Measurement, Characterisation and Strength Analysis, CA-Silo, Lyon, France, 119-140. 
Published in: Journal of Constructional Steel Research, 67(10), 1537-1544.

DOI: http://dx.doi.org/10.1016/j.jcsr.2011.03.028

Rotter J.M. (1997). "Design standards and calculations for imperfect pressurised axially compressed cylinders." Proc. Int. Conf. on Carrying Capacity of Steel Shell Structures, Brno, Czech Republic, 354-360.

Rotter J.M. (1998). "Development of proposed European design rules for buckling of axially compressed cylinders." Advances in Structural Engineering, 1(4), 273-286.

Rotter J.M. (2001). "Guide for the Economic Design of Circular Metal Silos.” Spon Press, London \& New York.

Rotter J.M. (2004). "Buckling of cylindrical shells under axial compression." Buckling of thin metal shells, J.G. Teng and J.M. Rotter, eds., Spon, London, 42-87.

Rotter J.M., Ooi J.Y. \& Zhong Z. (2006). "Critical pressure conditions in silos.” Proc. 5th International Conference for Conveying and Handling of Particulate Solids, Sorrento, Italy, 27-31.

Rotter J.M. (2008). "Silo and hopper design for strength.” Chapter 3 in Bulk Solids Handling Equipment Selection and Operation, D. McGlinchey ed., Blackwell, Oxford, 99-134.

Rotter J.M. \& Teng J.G. (1989). "Elastic stability of cylindrical shells with weld depressions." Jrnl. of Struct. Eng., ASCE, 115(5), 1244-1263.

Rotter J.M. \& Zhang Q. (1990). "Elastic buckling of imperfect cylinders containing granular solids.” Jrnl. of Struct. Eng., ASCE, 116(8), 2253-2271.

Sadowski A.J. \& Rotter J.M. (2010). "A Study of Buckling in Steel Silos under Eccentric Discharge Flows of Stored Solids." Jrnl. of Eng. Mech., ASCE, 136(6), 769-776.

Sadowski A.J. \& Rotter J.M. (2011). "Buckling of very slender metal silos under eccentric discharge.” Engineering Structures, 33(4), 1187-1194. 
Published in: Journal of Constructional Steel Research, 67(10), 1537-1544.

DOI: http://dx.doi.org/10.1016/j.jcsr.2011.03.028

Ummenhofer T., Peil U. \& Schulz U. (1997). "A rigorous model for assessing the buckling strength of silos." Proc. Int. Conf. on Carrying Capacity of Steel Shell Structures, Brno, Czech Republic, 91-97.

Yamaki N. (1984). "Elastic Stability of Circular Cylindrical Shells." Elsevier Applied Science Publishers, Amsterdam. 